\title{
SX-Ella Danis stent in massive upper gastrointestinal bleeding in cirrhosis - a case series
}

\author{
Mayank Jain, Mahadevan Balkrishanan, Chenduran SNK, Sridhar CGS, Ravi Ramakrishnan, Jayanthi Venkataraman \\ Gleneagles Global Health City, India
}

\begin{abstract}
We report our experience of three cases of decompensated cirrhosis with massive upper gastrointestinal bleeding, which required insertion of an SX-Ella Danis stent for hemostasis. The procedure is safe and effective.
\end{abstract}

Key words: endoscopy, cirrhosis, esophageal varices, gastrointestinal bleeding.

\section{Address for correspondence}

Mayank Jain, Gleneagles Global Health City, 439 Cheran Nagar, 600100 Chennai, India, phone: 917312365688 ,

e-mail: mayank4670@rediffmail.com

\section{Introduction}

Acute variceal bleeding is responsible for $70 \%$ of all upper gastrointestinal (UGI) bleeding episodes in patients with portal hypertension [1]. With improvement in treatment options and techniques, bleeding-related deaths have decreased from $42 \%$ to $15-20 \%$ in the past two decades [2]. However, there are clinical situations in which patients with massive bleeding are unmanageable despite advanced endoscopic and radiological interventions. Use of a removable, covered, self-expandable stent in recent times has been described to treat such bleeding esophageal varices [3]. We report our experience of three such cases which necessitated deployment of an SX-Ella Danis stent. Table 1 summarizes the details of the 3 cases.

\section{Case 1}

A 34-year-old male patient with decompensated cirrhosis and a MELD score of 35 presented to the emergency room with massive hemetemesis. He had hemodynamic instability, grade 3 hepatic encephalopathy and required vasopressor support. He was intubated in the intensive care unit and started on terlipressin intravenously ( $2 \mathrm{mg} 4$ hourly). Endoscopy showed grade 4 esophageal varices (modified Paquet classification) and variceal ligation was performed. Within 3 hours of variceal ligation, he again had torrential bleeding and an SX-Ella Danis stent was deployed. Hemostasis was achieved. However, the patient expired due to sepsis and multiorgan failure after 5 days of stent placement.

\section{Case 2}

The second case was an elderly gentleman with non-alcoholic steatohepatitis, decompensated cirrhosis, recurrent encephalopathy and renal dysfunction. He had undergone variceal ligation two weeks before and presented at our unit with a history of melena. Endoscopic examination showed large post-variceal ligation ulcers. Hemospray was used and hemostasis was achieved. However, two days later, he again had a massive hemetemesis and an SX-Ella Danis stent had to be used to control the bleeding. Despite the stent, he continued to have bleeding as noted by fresh blood in Ryle's tube and a fall in hemoglobin. Repeat endoscopy showed that the stent was not covering the most distal portion of the esophagus from where there was a persistent ooze. The stent was repositioned (Fig. 1) and finally hemostasis was achieved.

\section{Case 3}

This patient had alcohol-related decompensated chronic liver disease and was listed for living donor liver transplantation. He presented with massive UGI bleeding and hemodynamic instability. He was trans- 
Table 1. Clinical characteristics of our cases

\begin{tabular}{cccccccc}
\hline Case & Age/sex & $\begin{array}{c}\text { Etiology } \\
\text { of cirrhosis }\end{array}$ & Presentation & $\begin{array}{c}\text { Previous } \\
\text { endoscopic } \\
\text { procedures }\end{array}$ & $\begin{array}{c}\text { Indication } \\
\text { for stent } \\
\text { placement }\end{array}$ & $\begin{array}{c}\text { Complications } \\
\text { encountered }\end{array}$ & Outcome \\
\hline 1 & $34 / \mathrm{M}$ & $\begin{array}{c}\text { Wilson's } \\
\text { disease }\end{array}$ & $\begin{array}{c}\text { Massive UGl bleeding, } \\
\text { hemodynamic instability }\end{array}$ & None & Refractory Gl bleeding & None & $\begin{array}{c}\text { Hemostasis - achieved; death - secondary } \\
\text { to sepsis and multiorgan failure }\end{array}$ \\
\hline 2 & $68 / \mathrm{M}$ & $\begin{array}{c}\text { Non-alcoholic } \\
\text { steatohepatitis }\end{array}$ & $\begin{array}{c}\text { Post-EVL ulcer bleeding, } \\
\text { hemodynamic instability }\end{array}$ & $\begin{array}{c}\mathrm{EVL} \times 3 \\
\text { times }\end{array}$ & $\begin{array}{c}\text { Failure of hemospray } \\
\text { and massive Gl } \\
\text { bleeding }\end{array}$ & $\begin{array}{c}\text { Stent } \\
\text { repositioning } \\
\text { required }\end{array}$ & Hemostasis achieved \\
\hline 3 & $42 / \mathrm{M}$ & $\begin{array}{c}\text { Alcoholic } \\
\text { cirrhosis }\end{array}$ & $\begin{array}{c}\text { Massive UGl bleeding, } \\
\text { hemodynamic instability }\end{array}$ & None & $\begin{array}{c}\text { Refractory Gl } \\
\text { bleeding, failure } \\
\text { of EVL }\end{array}$ & $\begin{array}{c}\text { Stent } \\
\text { migration }\end{array}$ & Hemostasis achieved \\
\hline
\end{tabular}

ferred to an intensive care unit and started on terlipressin, vasopressors and antibiotics. Endoscopy showed grade 3 esophageal varices with red signs and active oozing. Variceal ligation was performed but he continued to have bleeding. In view of the persistent bleeding and worsening condition, a stent was placed and finally hemostasis could be achieved. Following the procedure, he showed a good recovery. The stent migrated into the stomach by day 4 and had to be removed.

\section{Discussion}

The SX-Ella Danis stent (Ella-CS, Hradec Kralove, Czech Republic) was first described by Hubbmann and his co-workers. They noted that the stent was easy to deploy, safe and effective in achieving hemostasis in all patients included in the pilot study [3]. The group's subsequent studies also showed similar results and they noted stent migration in up to 7 cases [4]. The stent,

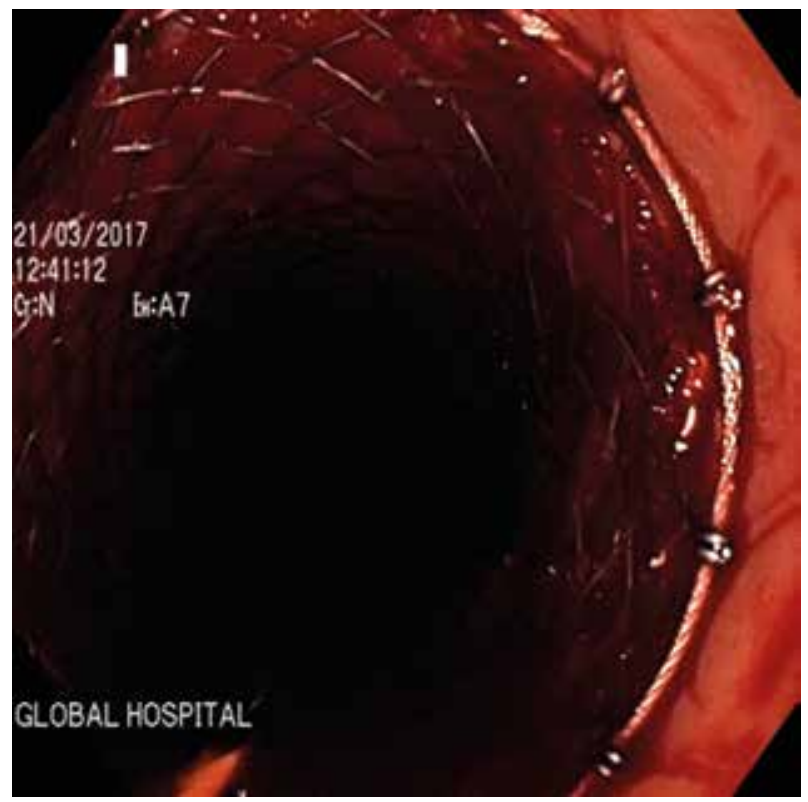

Fig. 1. Stent as seen during repositioning however, could be repositioned in all the cases by using the PEX-Ella extractor. Wright et al. used the stent in patients who were poor risk candidates for TIPS insertion or had contraindications for balloon tamponade. They reported effective hemostasis in $70 \%$ and observed that this stent placement may be used as an effective bridge to definite therapies such as TIPS [5]. The Baveno V consensus opines that a self-expanding covered esophageal metal stent may be an option in refractory esophageal variceal bleeding [6].

The SX-Ella Danis stent has atraumatic edges and radiopaque markers at both ends and at the midpoint to assess its position by a plain chest X-ray. Retrieval loops with gold markers at both stent ends allow the endoscopic extraction of the stent with a specifically designed system.

Potential indications for esophageal stenting include refractory variceal bleeding, large esophageal tears $[5,7]$ and banding or sclerotherapy-related ulcers [8]. The stent can be positioned for 7-14 days, thereby giving adequate time for the patient to fully recover from the bleeding, unlike the Sengstaken-Blakemore tube, which needs decompression and removal within 24 hours [6]. The stent however is not useful in bleeding gastric varices. In our series, we have used the stent in refractory UGI bleeding from varices or post-endoscopic variceal ligation (EVL) ulcers and obtained good results. We used the stent in patients who were unfit or had contraindications or failed on other conventional treatment options.

Advantages of the SX-Ella Danis stent include the presence of a security pressure valve that minimizes the risk of esophageal perforation. Early institution of an oral diet is possible with lowered risk of aspiration during subsequent endoscopy.

\section{Conclusions}

In our initial experience, we reaffirm that the SX-Ella Danis stent is safe, easy to deploy and achieves 
effective hemostasis. Stent migration is not uncommon. Further comparative data from variceal ligation and sclerotherapy are required to determine the impact of the use of this stent on short-term and longterm survival of patients and its cost-benefit impact in managing torrential variceal bleeders.

\section{Disclosure}

Authors report no conflict of interest.

\section{References}

1. D'Amico G, de Franchis R. Upper digestive bleeding in cirrhosis. Post-therapeutic outcome and prognostic indicators. Hepatology 2003; 38: 599-612.

2. Bosch J, Berzigotti A, Garcia-Pagan JC, et al. The management of portal hypertension: rational basis, available treatments and future options. J Hepatol 2008; 48: S68-S92.

3. Hubmann R, Bodlaj G, Czompo M, et al. The use of self-expanding metal stents to treat acute esophageal variceal bleeding. Endoscopy 2006; 38: 896-901.

4. Zehetner J, Shamiyeh A, Wayand W, et al. Results of a new method to stop acute bleeding from esophageal varices: implantation of a self-expanding stent. Surg Endosc 2008; 22: 2149-2152.

5. Wright $\mathrm{G}$, Lewis $\mathrm{H}, \mathrm{Hogan} \mathrm{B}$, et al. A self-expanding metal stent for complicated variceal hemorrhage: experience at a single center. Gastrointest Endosc 2010; 71: 71-78.

6. Laine L, Abid S, Albillos A, et al. Treatment of acute bleeding. In: Portal Hypertension V: Proceedings of the Fifth Baveno International Consensus Workshop. de Franchis R (ed.). Blackwell Publishing Ltd, Oxford 2011; 103-115.

7. Matull WR, Cross TJS, Yu D, et al. A removable covered self-expanding metal stent for the management of Sengstaken-Blakemore tube-induced esophageal tear and variceal hemorrhage. Gastrointest Endosc 2008; 68: 767-768.

8. Mishin I, Ghidirim G, Dolghii A, et al. Implantation of self-expanding metal stent in the treatment of severe bleeding from esophageal ulcer after endoscopic band ligation. Dis Esophagus 2010; 23: E35-E38. 